\title{
Usual and Unusual Gross Appearance of Hepatocellular Carcinomas
}

\author{
Keita Kai ${ }^{1}$, Atsushi Miyoshi², Kenji Kitahara², \\ Kohji Miyazaki2, Hirokazu Noshiro ${ }^{2}$ and Osamu Tokunaga ${ }^{1}$ \\ ${ }^{1}$ Department of Pathology \& Microbiology \\ ${ }^{2}$ Department of Surgery \\ Saga University Faculty of Medicine \\ Japan
}

\section{Introduction}

Hepatocellular carcinoma (HCC) usually shows a typical gross appearance and the gross classification and gross diagnosis of resected specimens is performed as routine clinical work. In the authors' institution, many surgical cases of HCC are encountered, including rare and unusual cases. This chapter documents the gross classification, features and diagnosis of usual and unusual HCCs with representative gross photographs and a review of the literature.

\section{Gross findings}

The gross appearances of HCCs are affected by various factors such as tumor size, tumor thrombus in the portal and hepatic veins, intrahepatic metastasis, necrosis and hemorrhage. Well-differentiated HCC often produces bilirubin and the tumor color will be greenish after formalin fixation. On the other hand, poorly differentiated HCC usually shows a whitish coloration on gross appearance. If the tumor is accompanied by steatosis, the tumor will be yellowish in color. HCC frequently presents with a nodular appearance showing fibrous capsules and septa. The occurrence of capsule and septum formation is closely related to tumor size. Both capsule and septum are unusual in small HCCs less than $2.0 \mathrm{~cm}$ in diameter. In the majority of HCCs over $2.0 \mathrm{~cm}$ in diameter, the tumor grows expansively and a capsule and septum are formed.

\section{Gross classification of usual types of HCC}

\subsection{Eggel's classification}

Eggel's classification [Eggel, 1901] was proposed more than 100 years ago, and has been widely used for the classification of autopsy cases, rather than surgical cases. This system classifies HCC into three major types according to gross appearance: nodular; massive; and diffuse. Nodular type consists of a single or multiple discrete nodular tumors with clear demarcation. Massive type is a large mass replacing almost the entire right or left lobe. Diffuse type is characterized by diffuse proliferation of numerous minute cirrhosis-like tumor nodules throughout the entire lobe or liver. 


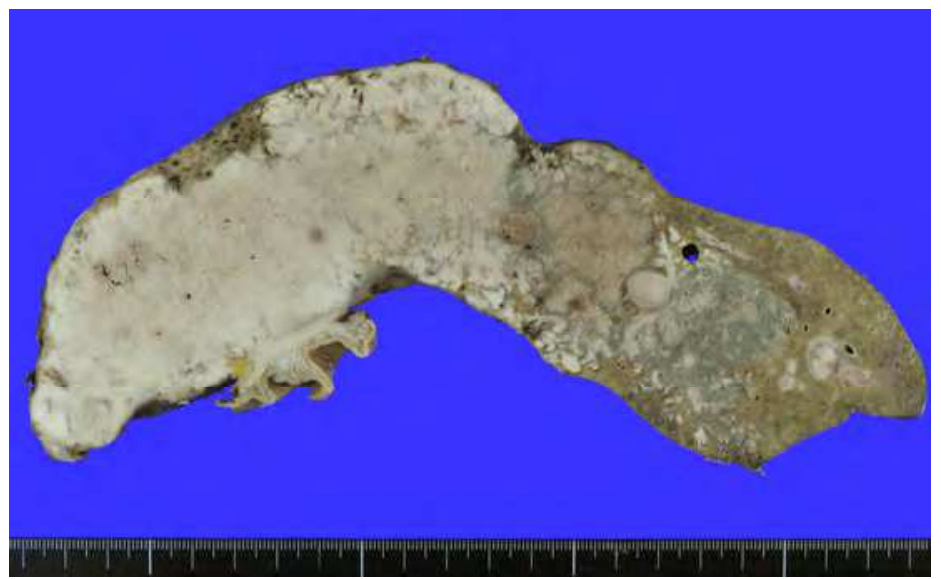

Fig. 1. Gross appearance of massive-type HCC in Eggel's classification.

\subsection{Subclassification of nodular HCC}

Eggel's classification is not applicable to many surgically resected HCCs. In order to cope with surgically resected HCCs, the Liver Cancer Study Group of Japan (LCSGJ) divided nodular HCC into three subtypes: simple nodular type; simple nodular type with extranodular growth; and confluent multinodular type [Kanai et al., 1987; LCSGJ, 1987]. The category of small nodular type with indistinct margin, as the typical gross appearance of early HCC, has recently been added to this subclassification [LCSGJ, 2000]. Several investigators have reported the predictive value of this subclassification, with favorable outcomes for simple nodular type compared to the other two subtypes in terms of recurrence and survival after hepatectomy [Hui et al., 2000; Shimada et al., 2001; Inayoshi et al., 2003].

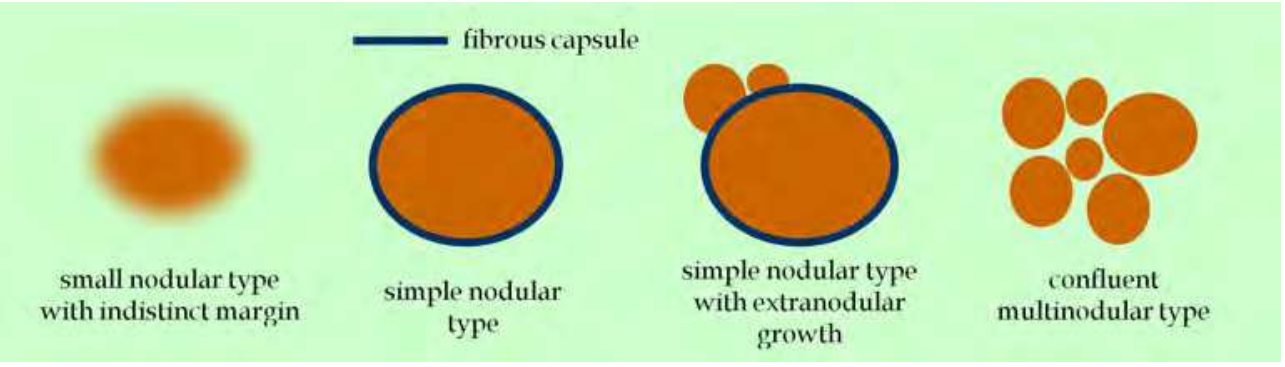

Fig. 2. Schema for subclassification of nodular HCC on gross appearance

\subsubsection{Small nodular type with indistinct margins}

Grossly, small HCC less than about $2 \mathrm{~cm}$ in diameter can be classified into two major types: a small nodular type with indistinct margins (vaguely nodular type); and a distinctly nodular type [Kojiro \& Nakashima, 1999]. The distinctly nodular type can be classified into one of the three subtypes: simple nodular type; simple nodular type with extranodular growth; and confluent multinodular type. On gross observation of the small nodular type 
with indistinct margins, distinguishing an obscure tumor nodule from surrounding cirrhotic liver is sometimes difficult. Histologically, most tumors of small nodular type with indistinct margins consist of uniformly distributed well-differentiated cancerous tissue showing a characteristic replacing growth at the tumor boundary. Although portal tracts are retained within the nodule, the number is markedly reduced [Nakashima et al., 1999]. Many of the retained portal tracts are deformed due to varying degrees of tumor cell invasion, designated as "stromal invasion", and this stromal invasion is regarded as the most helpful clue to distinguish small well-differentiated HCC from high-grade dysplastic nodules [Kondo et al., 1994, Tomizawa et al., 1995, Nakano et al, 1997]. Vascular invasion and intrahepatic micrometastasis are not usually observed in small nodular-type HCC with indistinct margins. Well-differentiated HCC of the small nodular type with indistinct margins has thus been designated as "early hepatocellular carcinoma", to separate this particular type of HCC from the classical form of HCC [Kojiro, 2006, 2007].

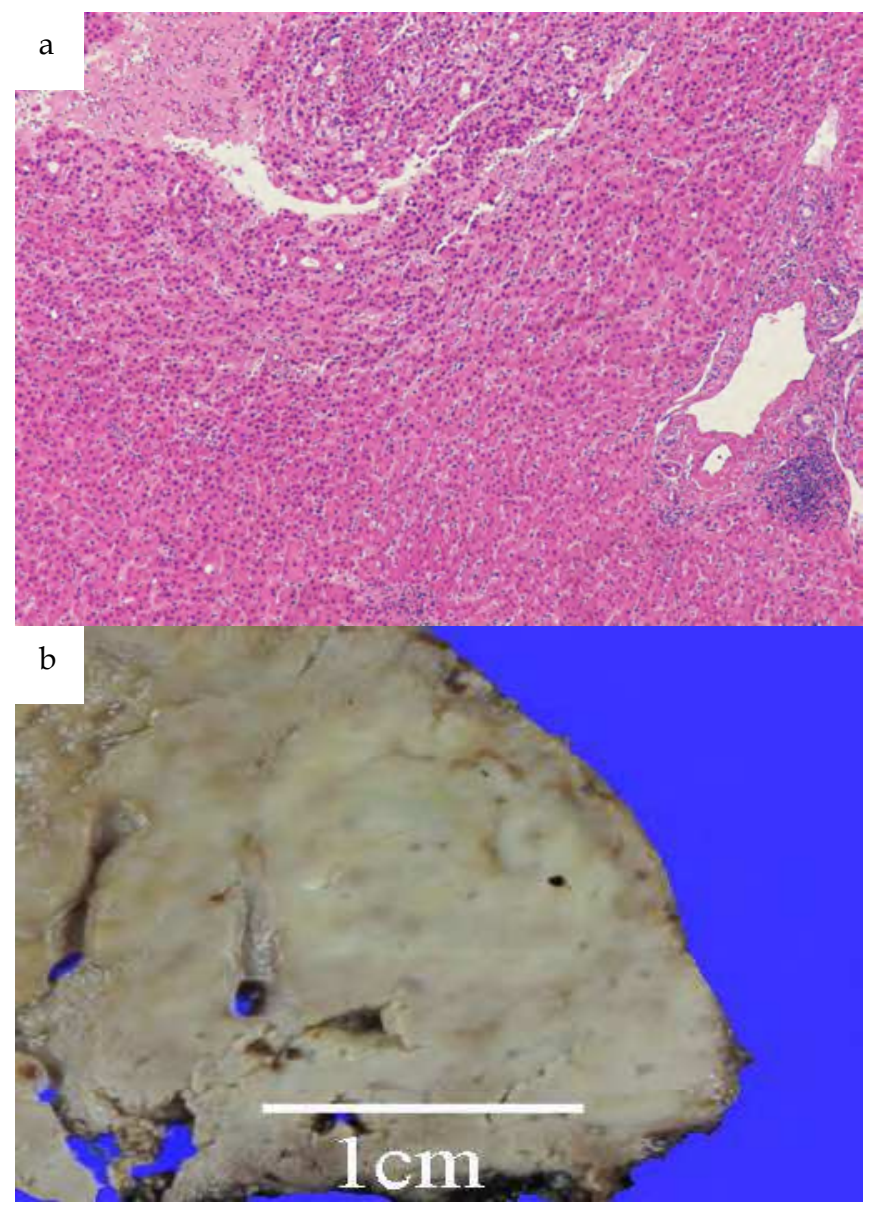

Fig. 3. a) Gross appearance of small nodular type with indistinct margins. b) Characteristic replacing growth at the tumor boundary (hematoxylin and eosin $(\mathrm{HE}), \times 20)$. 


\subsubsection{Simple nodular type}

This is a well-demarcated nodule, frequently surrounded by a fibrous capsule. Grossly, extranodular tumor growth, intrahepatic metastasis, and/or vascular invasion are not observed. The inside of the tumor often shows a mosaic appearance due to fibrous septa. Small HCC of the distinctly nodular type is also included in this category.

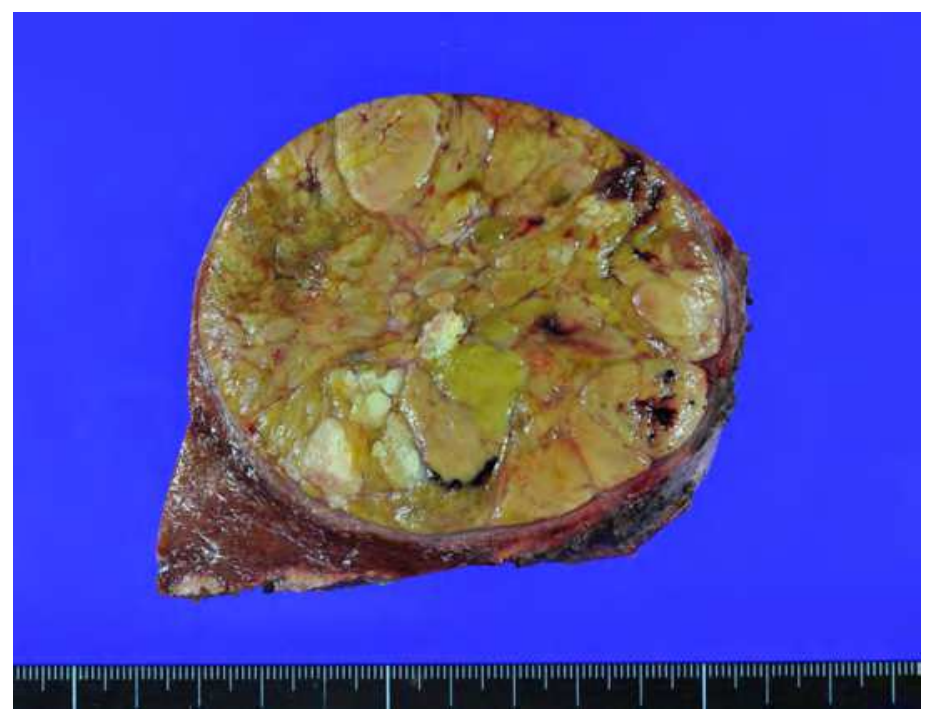

Fig. 4. Gross appearance of simple nodular type. A fibrous capsule and mosaic appearance due to fibrous septa are apparent.

\subsubsection{Simple nodular type with extranodular growth}

When a tumor of simple nodular type shows varying degrees of extranodular growth beyond the capsule, vascular invasion, and/or small metastases near the nodule, the tumor should be categorized as simple nodular type with extranodular growth. This criterion is not concerned with tumor size. Small tumors showing simple nodular type with extranodular growth sometimes need discrimination from confluent multinodular type and large tumors showing simple nodular type with extranodular growth sometimes need discrimination from massive-type HCC. 


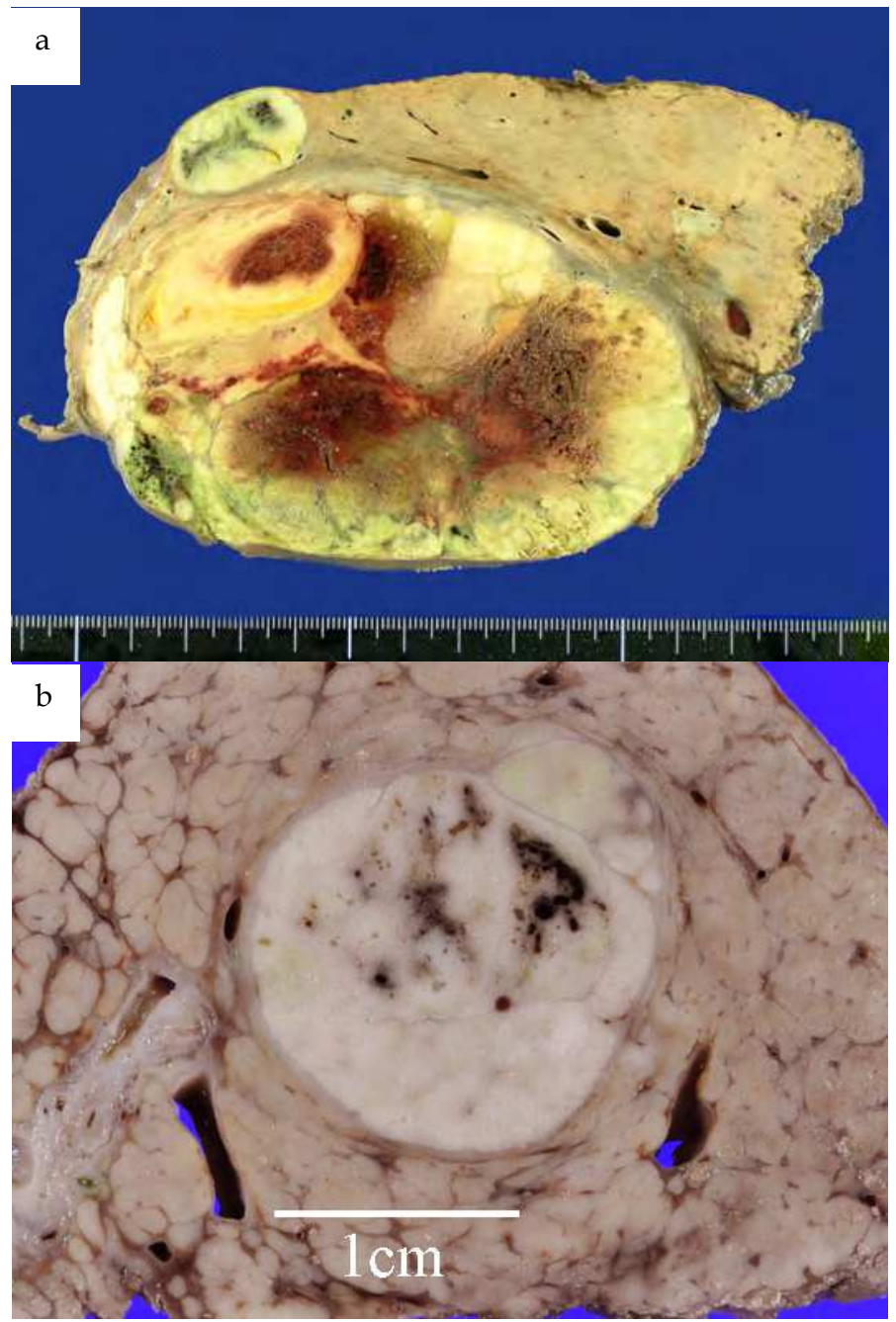

Fig. 5. Gross appearance of simple nodular type with extranodular growth. a) Small tumor of simple nodular type with extranodular growth. b) Large tumor of simple nodular type with extranodular growth. This type of tumor sometimes needs discrimination from massive-type and/or confluent multinodular-type HCC.

\subsubsection{Confluent multinodular type}

This is a tumor resulting from the joining together of a few to numerous small tumor nodules. No fibrous capsule is seen covering the entire tumor in this type and portal tracts are frequently entrapped between agglomerated small tumor nodules. The incidence of vascular invasion and/or intrahepatic metastasis is higher than in simple nodular types. Large confluent multinodular-type tumors sometimes need discrimination from massivetype HCC. 


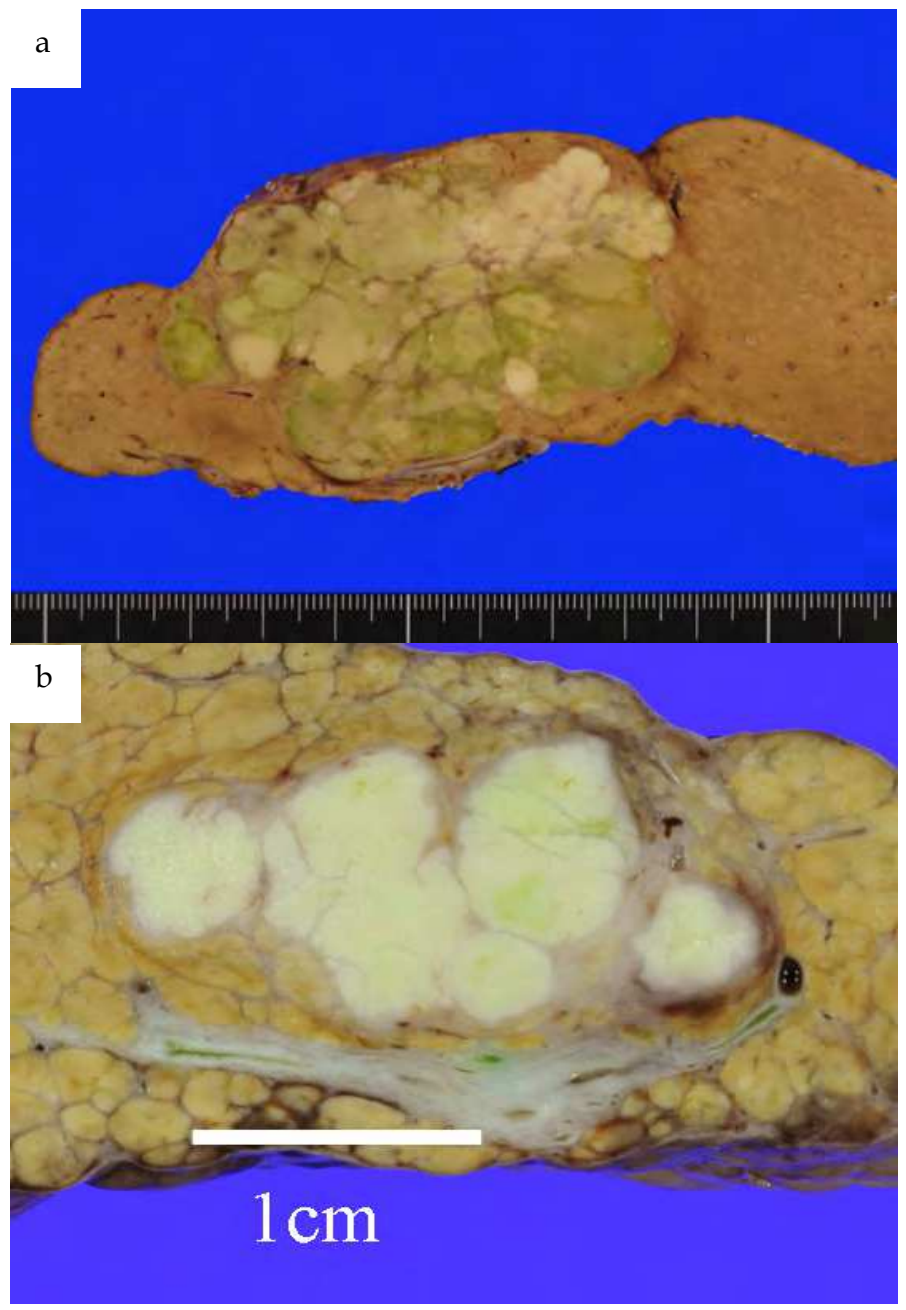

Fig. 6. Gross appearance of confluent multinodular-type HCC. a) Small tumor of confluent multinodular type. b) Large tumor of simple confluent multinodular type. No fibrous capsule covering the entire tumor is present.

\section{Unusual gross types of HCC}

\subsection{Scirrhous HCC}

About $5 \%$ of HCCs show a scirrhous growth pattern characterized by marked fibrosis along the sinusoid-like blood spaces with varying degrees of atrophy of the tumor trabeculae [Kurogi et al., 2006]. These tumors are subclassified as scirrhous HCC according to the WHO classification [Bosman et al., 2010]. Macroscopically, scirrhous HCCs are greyish-white, solid, lobulated, and unencapsulated, but well demarcated, stellate-shaped fibrosis is common. The gross appearance of scirrhous HCC mimics intrahepatic cholangiocarcinoma, 
combined hepatocellular and cholangiocarcinoma, and fibrolamellar carcinoma. Scirrhous HCC is histologically distinguishable from fibrolamellar carcinoma, because the cancer cells do not differ from those of ordinary HCC. Scirrhous HCC should also not be confused with diffuse fibrosis (scirrhous change) in HCC, a well-known feature of cases treated by various anticancer therapies such as chemotherapy, irradiation and chemoembolization. Preoperatively, scirrhous HCC is often misdiagnosed as intrahepatic cholangiocarcinoma or metastatic carcinoma on diagnostic imaging, because of atypical imaging findings due to the diffuse fibrosis [Kojiro, 2006; Bosman et al., 2010].

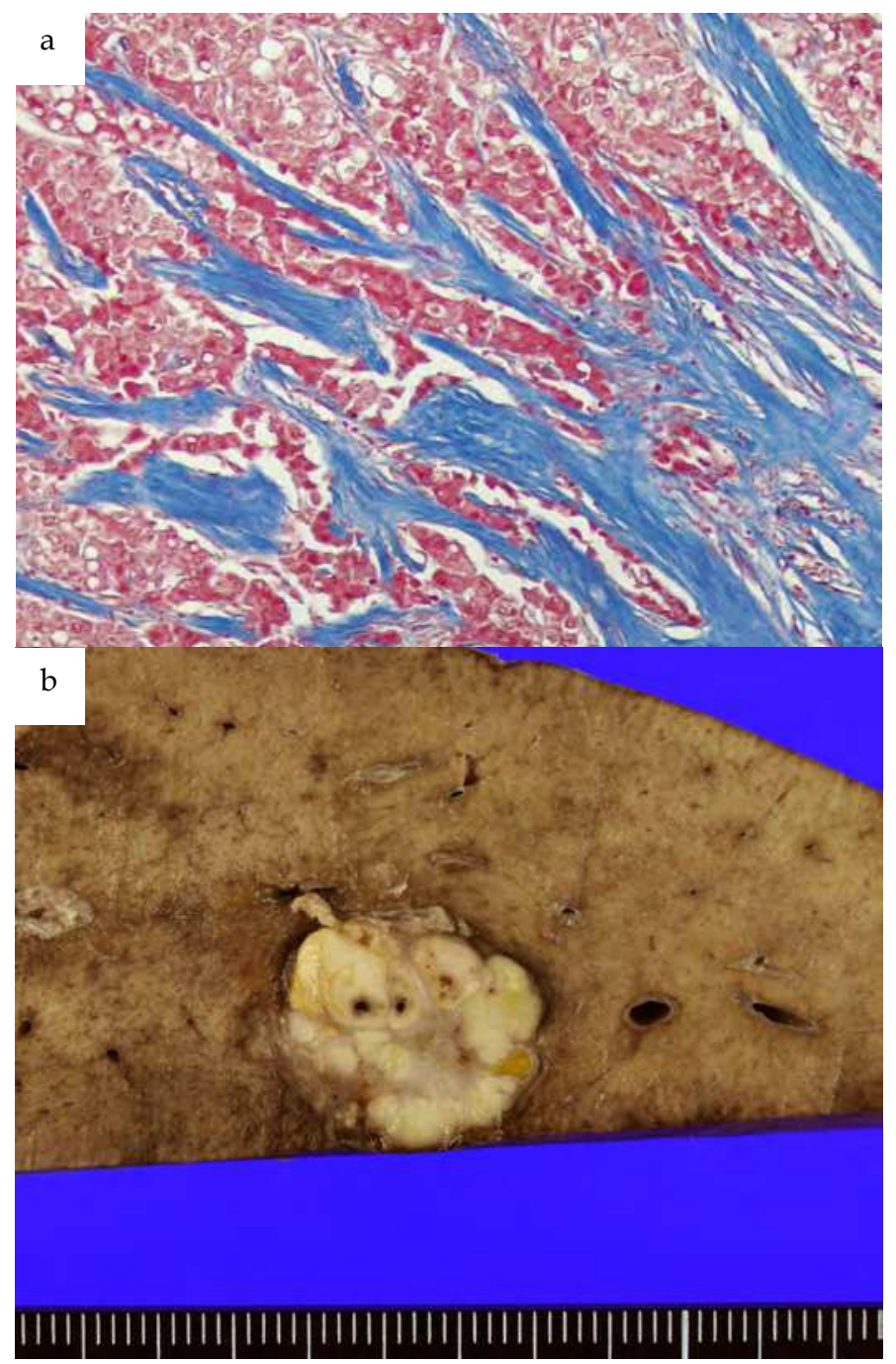

Fig. 7. a) Gross appearance of scirrhous HCC. Stellate-shaped fibrosis is present. b) Histology of the scirrhous HCC. Marked fibrosis (blue) is apparent along the sinusoid-like blood spaces. Cancer cells are no different from ordinary HCC (Azan staining, $\times 100$ ). 


\subsection{Fibrolamellar HCC}

The clinical and pathological features of fibrolamellar HCC (FLC) were first described by Edmondson [Edmondson, 1958]. The term "fibrolamellar carcinoma" was proposed by Craig et al. [Craig et al., 1980], and has been adopted worldwide. FLC shows marked geographic variations in incidence, and is extremely rare in Asian countries, including Japan [Magata et al., 2001]. Soreide et al. [Soreide et al., 1986] reviewed 80 cases of FLC (including their own 9 cases) reported between 1980 and 1986. This entity most frequently occurs in noncirrhotic livers of adolescents or young adults with a mean age of 23 years; only $6 \%$ are over 50 years old. Two thirds of the cases of FLC involve the left lobe and prognosis is more
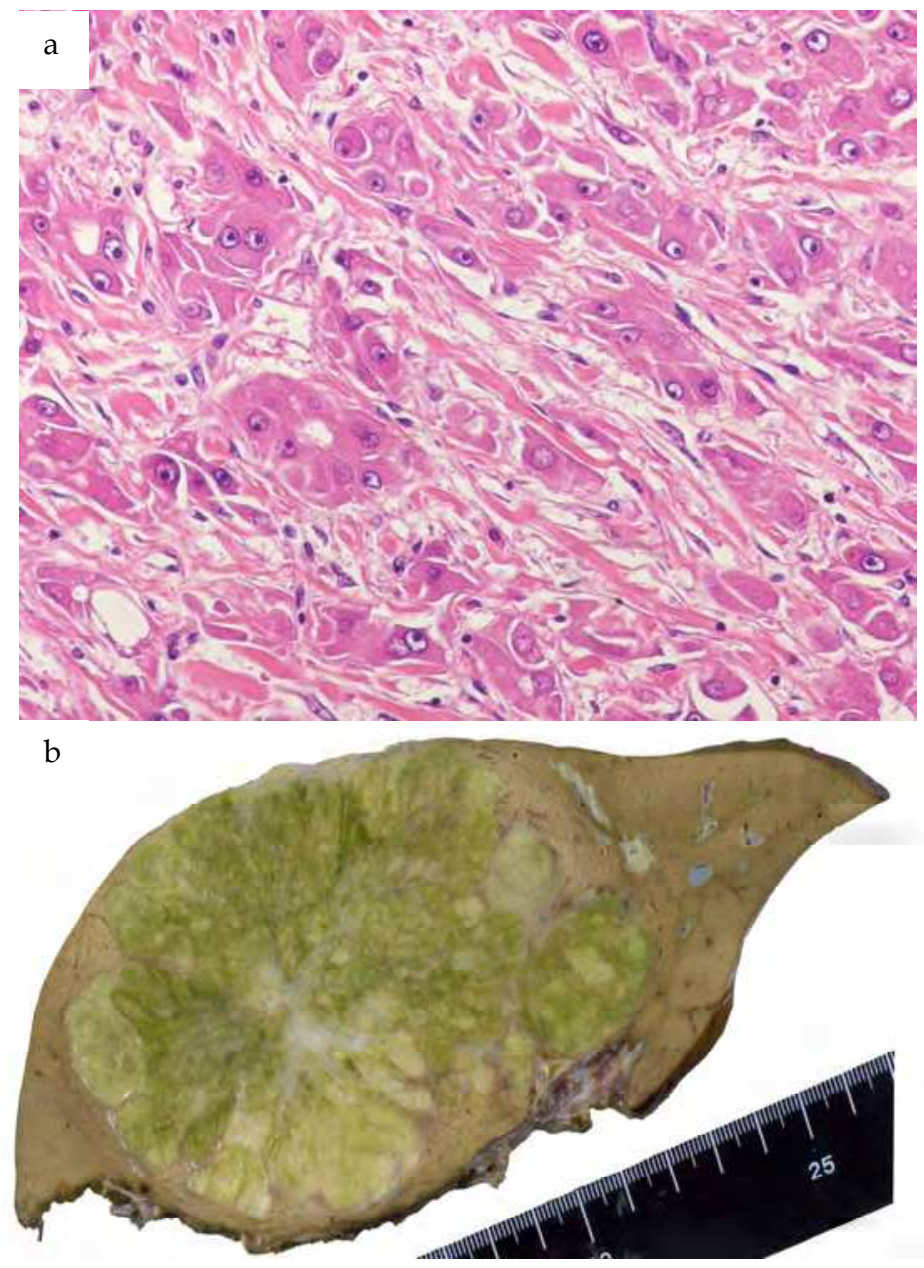

Fig. 8. a) Gross appearance of fibrolamellar hepatocellular carcinoma. White fibrous septa forming a central scar, lobulated appearance, and greenish coloration due to bile production can be observed. b) Tumor cells display abundant polygonal and deeply eosinophilic cytoplasm and characteristic lamellar fibrosis is observed $(\mathrm{HE}, \times 200)$. 
favorable than that of classical HCC. Grossly, the tumor is well demarcated but nonencapsulated and is light brown, tan or gray. The tumor is occasionally partially greenish due to bile production. Glistening white fibrous septa, sometimes forming a central scar, give the tumor a lobulated appearance. This gross appearance mimics focal nodular hyperplasia. Histologically, this particular type of HCC consists of tumor cells growing in sheets or small trabeculae, which are separated by fibrous collagen with a characteristic lamellar pattern of variable thickness and frequent hyalinization. Tumor cells display abundant polygonal and deeply eosinophilic cytoplasm and a distinct nucleolus. Intracytoplasmic inclusions, such as "pale bodies" that show immunohistochemically positive results for antifibrinogen and PAS-positive globules, are frequently observed [Ishak et al., 1999].

\subsection{Green HCC}

Nodular-type HCC accompanied by prominent bile production shows a yellowish coloration on a fresh specimen and deep greenish coloration after formalin fixation. Such tumors are generally called "green $\mathrm{HCC}^{\prime}$.

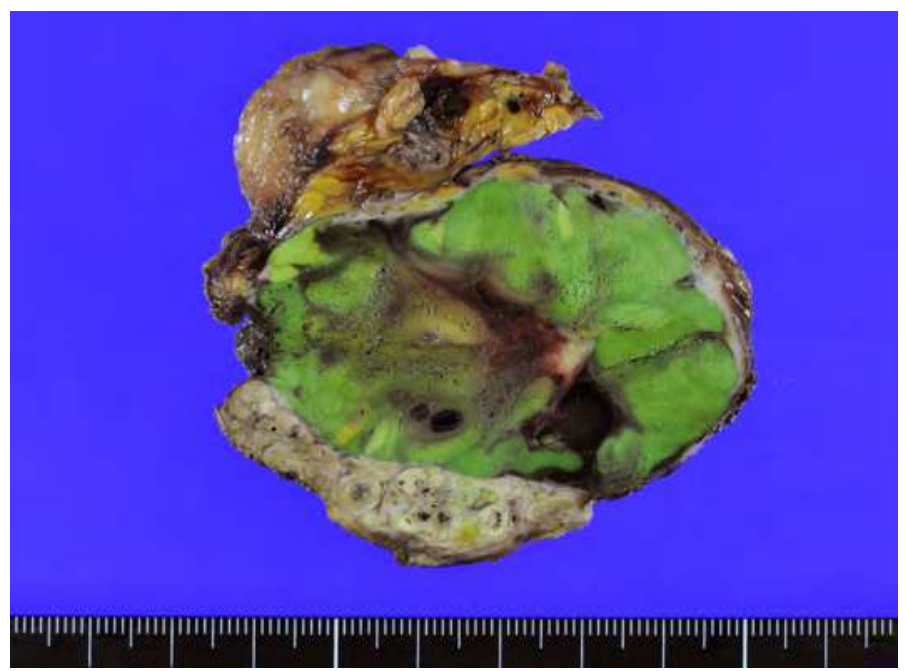

Fig. 9. Gross appearance of green HCC.

\subsection{Pelioid type of HCC}

Peliosis hepatis-like blood-filled cavities are frequently observed in HCC. HCC with this finding is generally called "HCC with peliotic change" or "pelioid-type HCC" [Ishak et al., 1999]. Another characteristic of HCC with peliotic change is that all tumors are completely or incompletely encapsulated. Several cases of extensive pelioid-type HCC have been reported [Kim, 2007, Hoshimoto, 2009, Kai, 2011]. Grossly, extensive pelioid-type HCC mostly consists of well-defined black-nodular components. Histologically, peliotic change is distinguished from hemorrhage by the presence or absence of degenerative changes and/or necrosis. In general, degenerative changes and/or necrosis are observed around 
hemorrhage in HCC tumors. On the other hand, the tumorous tissue around peliotic change is not at all degenerative or necrotic, and blood is localized within the spaces with clear margins. However, when peliotic change becomes extensive, rupture may occur and hemorrhage may develop [Kojiro, 2006].

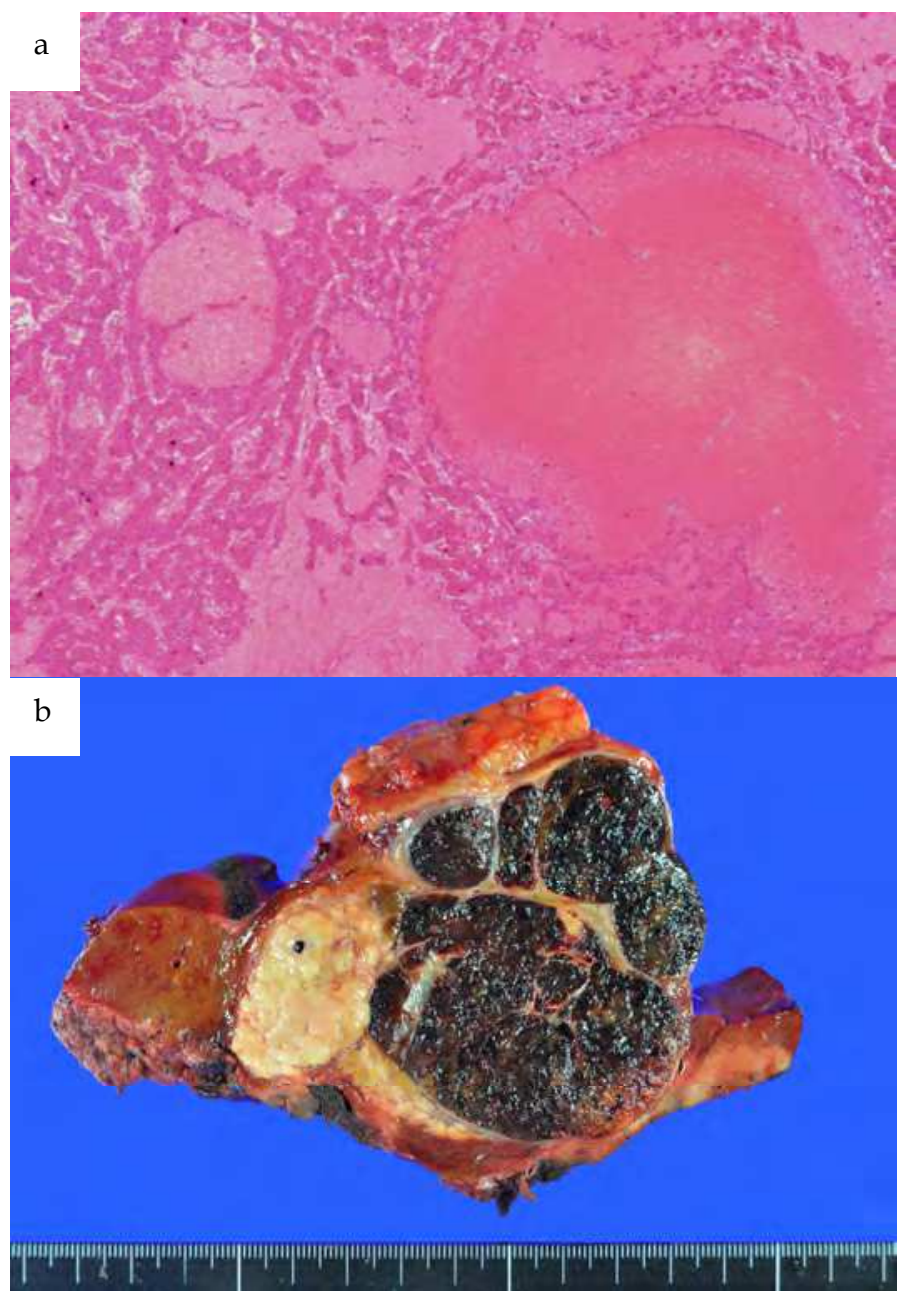

Fig. 10. a) The gross appearance of pelioid-type HCC. The tumor comprises well-defined black nodular components and white nodular components. b) Histologically, extensive pelioid change is apparent in the tumor tissue $(\mathrm{HE}, \times 25)$.

\subsection{Intraductal growth type of HCC}

Rarely, HCC shows growth into the hepatic bile duct and/or common bile duct, causing progressive obstructive jaundice. In 1972, Lin [Lin, 1972] designated such cases as "icteric $\mathrm{HCC}^{\prime \prime}$. The reported incidence of icteric HCC varies from $0.2 \%$ to $5.4 \%$ in patients with HCC 
[Kojiro et al., 1982; Huang et al., 1998]. Although intraductal tumor growth of HCC was once considered rare, advances in diagnostic imaging have revealed many cases of HCC presenting with intra-bile-duct growth [Kirk et al., 1994; Soyer et al., 1995; Wang et al., 2002]. Patients with the intraductal growth type of HCC rarely show no obvious intrahepatic tumor. Postoperative pathological examinations confirm the bile duct nodules causing obstructive jaundice as HCC. This type of HCC is difficult to diagnose, and only a few cases have been reported [Long et al., 2010]. In some cases, massive hemorrhage in the bile duct (hemobilia) forms due to tumor growth and can cause rapid death on rare occasions [Kojiro, 2006]. Huang et al. [Huang et al., 1998] stated that the prognosis might be improved if surgical resection of the tumor cast is performed at an earlier stage. In fact, many cases have been reported with good prognosis after tumor cast resection [Chen et al., 1994; Lau et al., 1997; Hu et al., 1999].

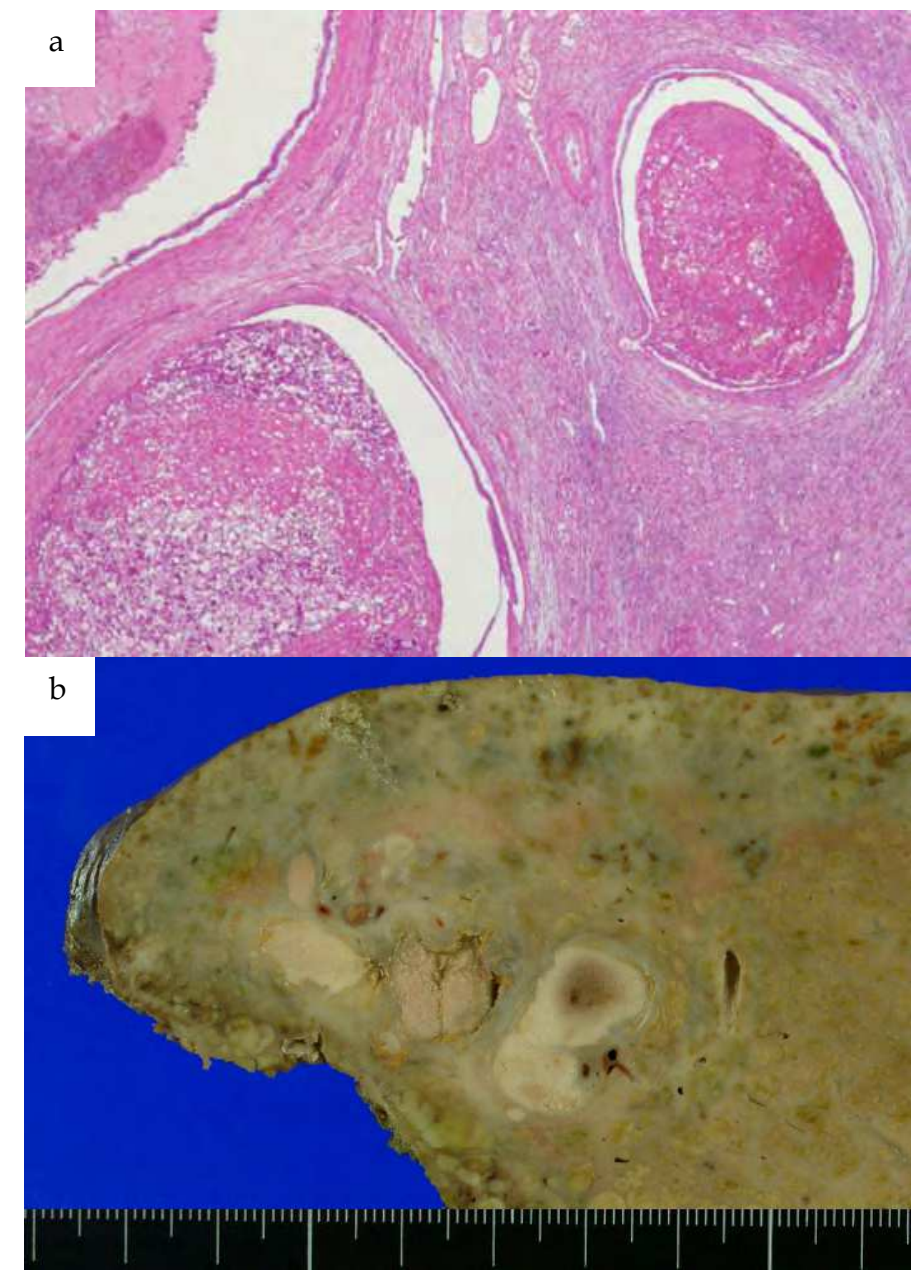

Fig. 11. a) Gross appearance for the intraductal growth type of HCC. This case shows no obvious intrahepatic mass lesion. b) Tumor cells with blood clot in dilated bile ducts $(\mathrm{HE}, \times 20)$. 


\subsection{Spontaneous regression of HCC}

Spontaneous massive necrosis or regression of HCC is a very rare event. The precise mechanisms underlying spontaneous regression of HCC remain unclear, but various factors

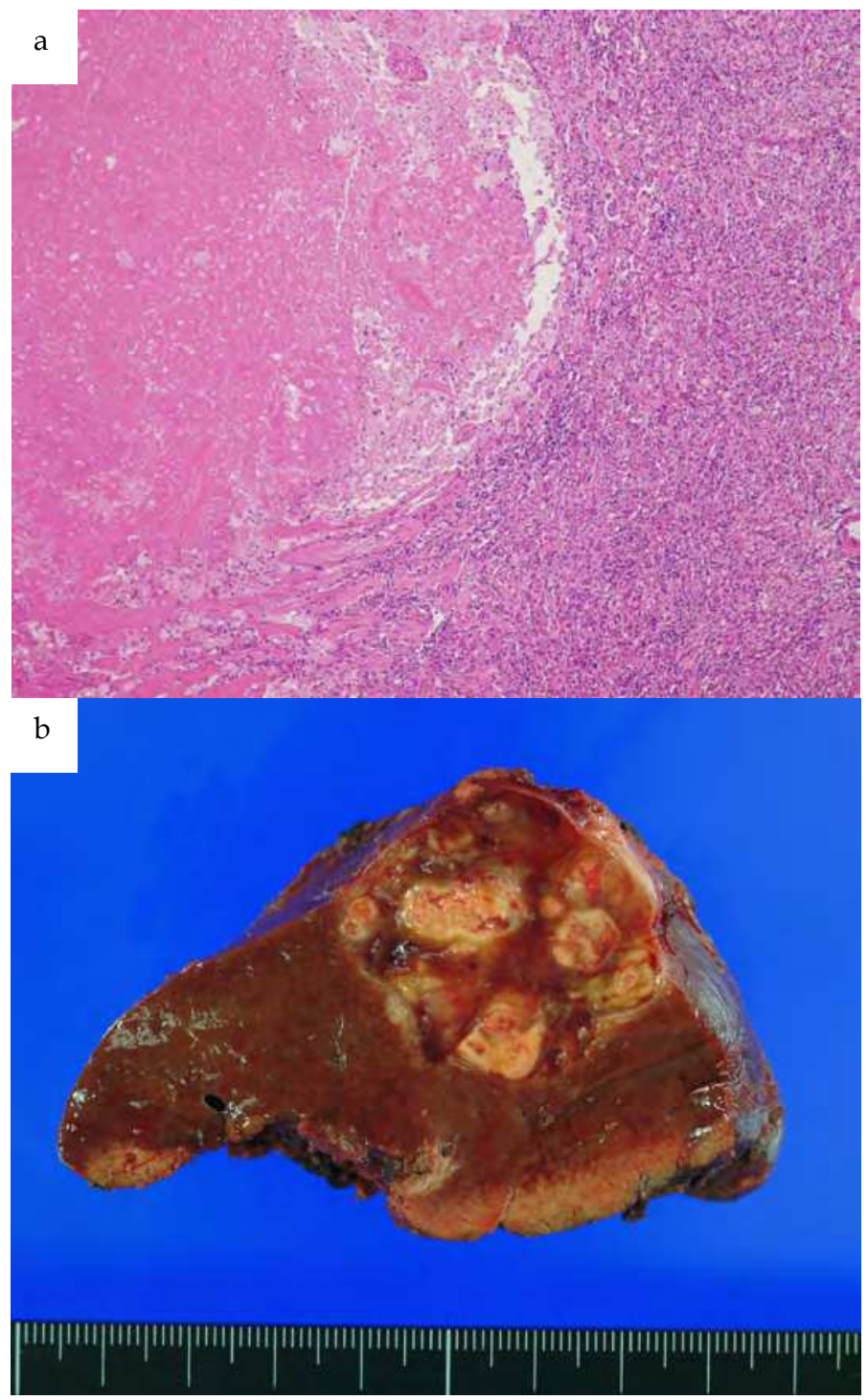

Fig. 12. a) Cut surface of the resected liver in a case of spontaneous regression. Yellow-white nodular lesions and brownish lesions coexist. The HCC measuring $11 \mathrm{~cm}$ in diameter showed a significant reduction to $3.7 \mathrm{~cm}$ after angiography. b) Coagulative necrosis and inflammatory granulation tissue are apparent in the nodule and small foci of viable HCC cells are observed in another specimen $(\mathrm{HE}, \times 40)$. 
have been speculated to play a role, such as alcohol withdrawal, androgen withdrawal, and intake of herbal medicines [Gottfried et al., 1982; Lam et al., 1982; McCaughan et al., 1985]. Secondary stimulation of cytokine production by tumor necrosis or bacterial infection has also been suggested to contribute to spontaneous regression [Watanabe et al., 1994; Markovic et al., 1996]. Another important factor might be insufficient blood supply to the tumor, possibly due to rapid natural tumor growth, spontaneous arterial thrombosis, thickened fibrous capsule or gastrointestinal bleeding [Suzuki et al., 1989; Gaffey et al., 1990; Tocci et al., 1990; Imaoka et al., 1994; Nakajima et al., 2004]. A few cases of spontaneous regression of HCC after angiography have been reported [Takayasu et al., 1986; Kai et al., 2010]. The characteristic histology in these cases is coagulative necrosis of tumor cells and inflammatory granulation tissue surrounding the coagulative necrosis. Grossly, yellowwhite nodular lesions reflecting coagulative necrosis and brownish lesions reflecting inflammatory granulation tissue coexist.

\section{Differential diagnosis by gross appearance}

Various tumors and tumor-like lesions can arise in the liver. Some of these tumors show a similar gross appearance to HCC, but some are easily discriminated from HCC on gross appearance.

\subsection{Intrahepatic cholangiocellular carcinoma}

Intrahepatic cholangiocellular carcinoma (ICC) is also grossly classified into three types: mass-forming type; periductal infiltrating type; and intraductal growth type. Within these three types, the mass-forming type is grossly nominated as a differential diagnosis of classical HCC. This differential diagnosis is usually easily achieved based on the characteristic gross appearance of mass-forming ICC, such as a lobulated, firm and solid

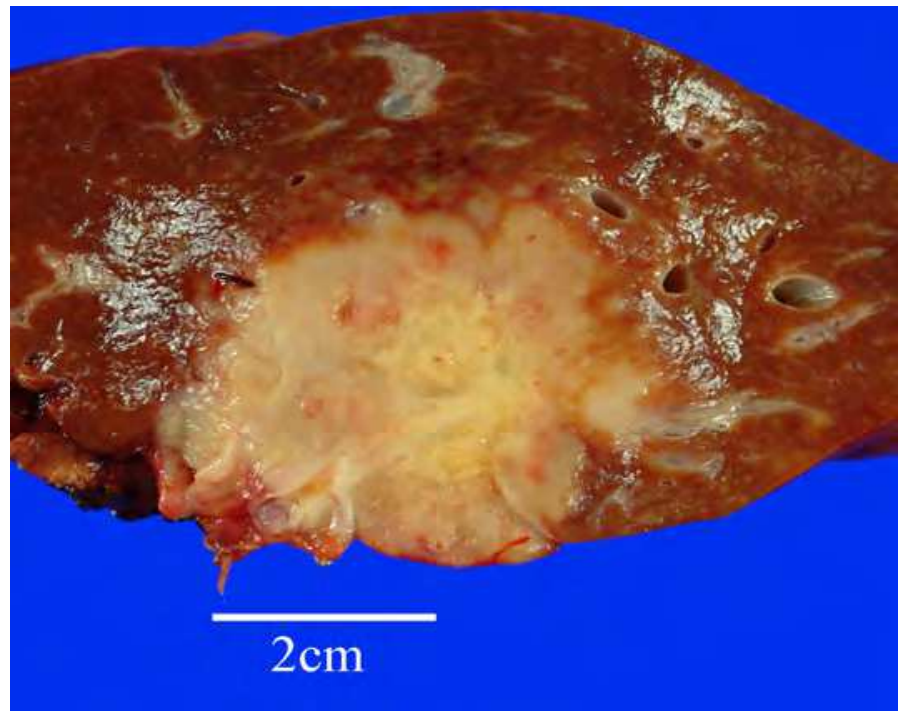

Fig. 13. Cut surface of the mass-forming type of ICC. 
gray to gray-white mass without a fibrous capsule and often with central necrosis or scarring. Scirrhous-type HCC sometimes mimics mass-forming ICC. Intraductal growthtype HCC often mimics intraductal growth-type ICC and discrimination based on gross appearance is difficult.

\subsection{Cholangiolocellular carcinoma}

Cholangiolocarcinoma is a rare neoplasm with a reported incidence of $0.8-1.0 \%$ among primary liver cancers [Steiner \& Higginson, 1959; Shiota et al., 2001]. Cholangiolocarcinoma

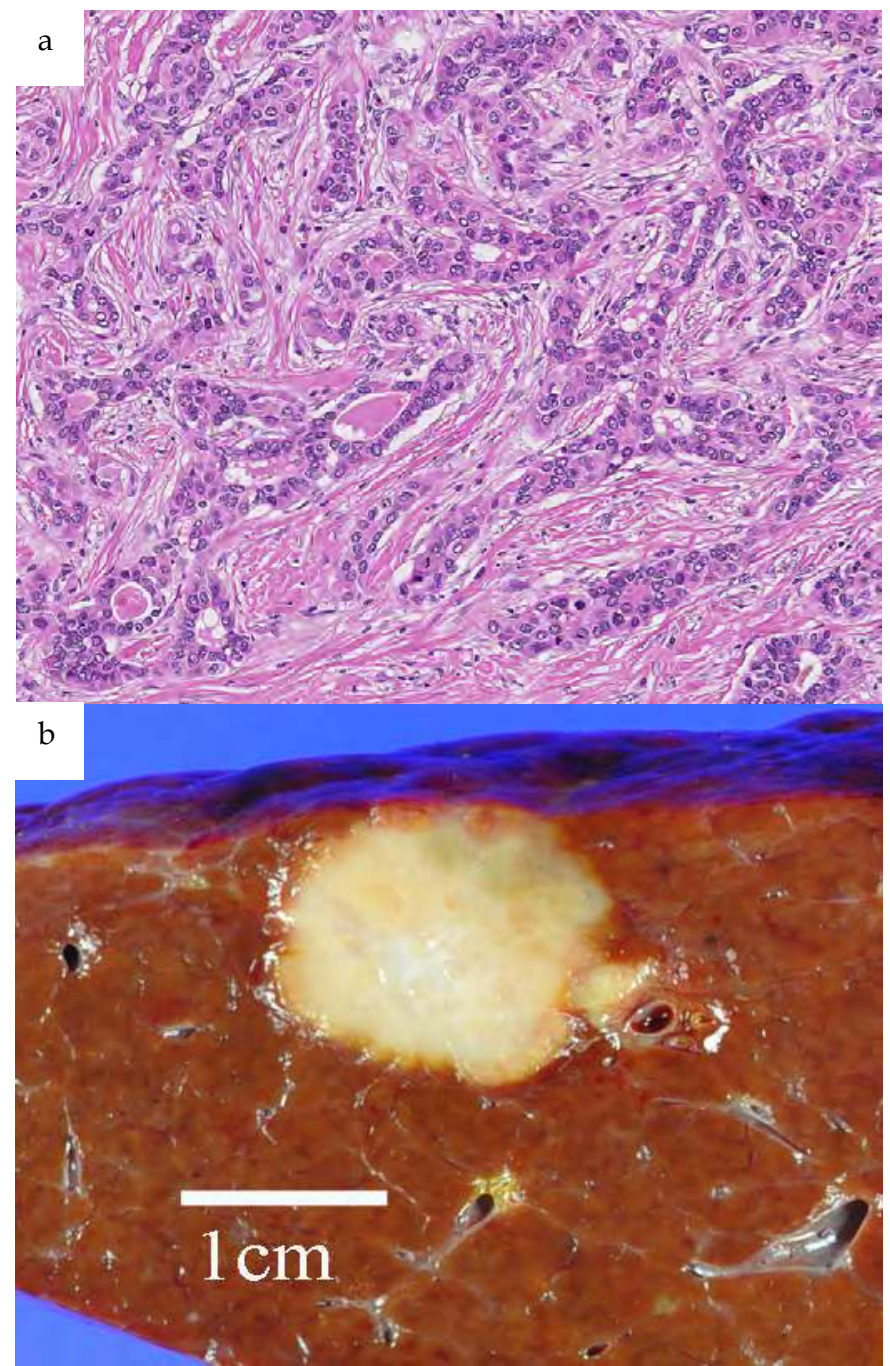

Fig. 14. a) Gross appearance of cholangiolocellular carcinoma. b) A tubular cordlike anastomosing pattern (as the so-called "antler pattern") of tumor cells (HE, $\times 100)$. 
is now considered to be derived from Hering's canal or stem cells, which have intermediate features between hepatocytes and bile duct epithelium [Shiota et al., 2001; Kojiro, 2006]. Grossly, cholangiolocarcinoma is whitish in color and solid, not encapsulated, and resembles cholangiocellular carcinoma. Histologically, tumor cells display eosinophilic cytoplasm with ovoid nuclei, and mild atypia, and adopt a tubular cordlike anastomosing pattern (so-called antler pattern). These cell cords are continuous with liver cell cords at the tumor boundaries, showing a replacing pattern.

\subsection{Hepatocellular adenoma (HCA)}

HCA is a benign liver neoplasm comprising hepatocyte-like tumor cells. The incidence of HCA is about 3-4 per 100000 population in Western countries [Rooks et al., 1979], but is

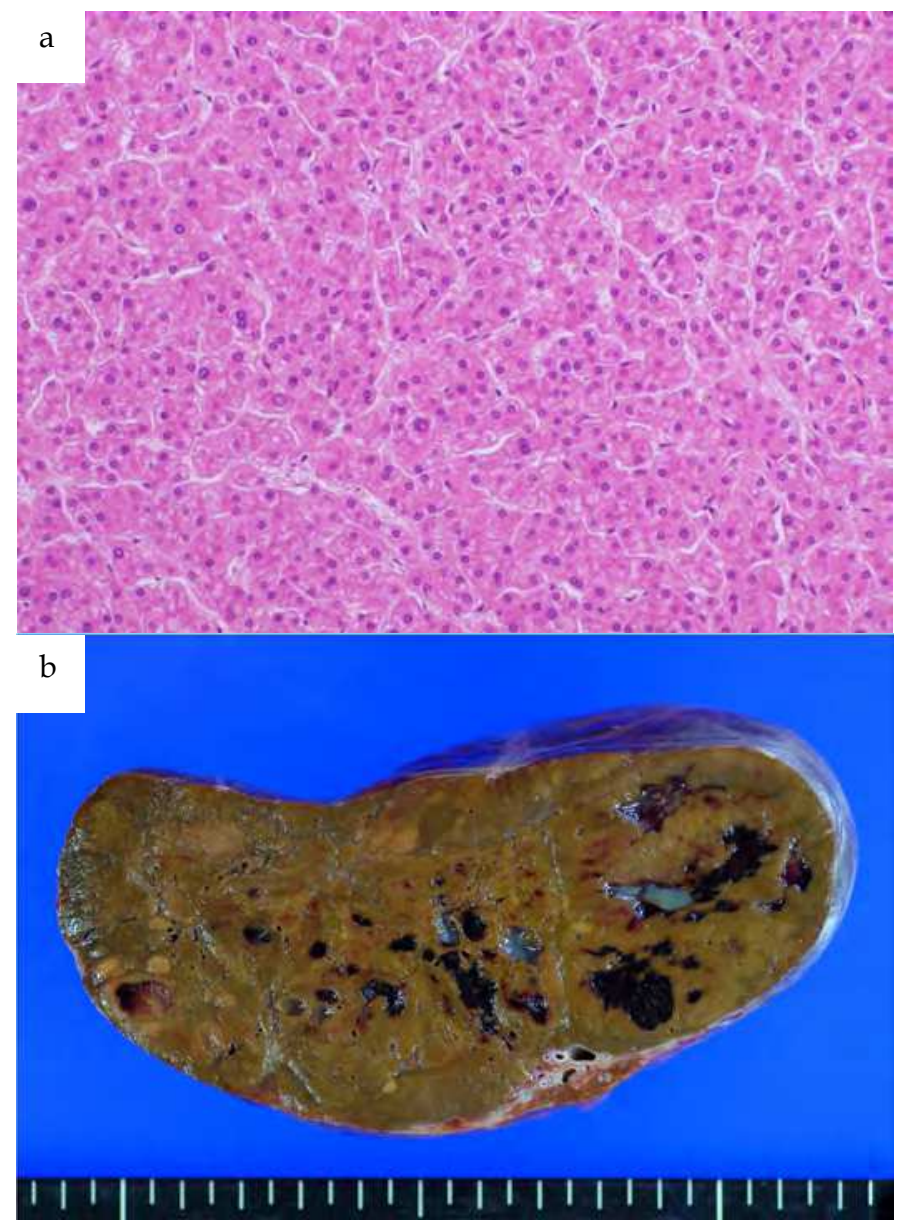

Fig. 15. a) Gross appearance of hepatocellular adenoma. Focal peliotic change is present. b) The nodule consists of tumor cells with abundant hydropic cytoplasm and little atypia arranged in a trabecular pattern. 
lower in Japan and Asian countries. HCA predominantly occurs in females in the third and fourth decades of life, and a close etiological relationship between HCA and oral contraceptives has been described [Ishak \& Rabin, 1975]. Patients taking androgens for Fanconi anemia or acquired anaplastic anemia are also at risk [Velazquez \& Alter, 2004]. Nonhormonal risk factors include glycogenosis type 1 (von Gierke disease) or 3 (Forbes disease), galactosemia, tyrosinemia, familial polyposis coli, and hepatic iron overload with $\beta$-thalassemia [Shuangshoti \& Thaicharoen, 1994]. Obesity has recently been shown to be a risk factor for a particular HCA subtype [Bosman et al., 2010]. Grossly, HCA is found in the normal liver as a well-demarcated, single or multiple solid tumor. Many HCAs are not encapsulated, but some are partly or entirely encapsulated. The tumor is yellowish and solid, sometimes associated with necrosis and hemorrhage and/or peliosis hepatis-like (pelioid) change and the tumor may be divided by fibrous septa. HCA developing close to the liver surface can protrude outside the liver, and is thus susceptible to rupture. Histologically, HCA consists of tumor cells with abundant hydropic cytoplasm and little atypia arranged in a trabecular pattern of one- or two-cell-thick plates, or round eosinophilic tumor cells in a thin trabecular pattern. However, because the sinusoid-like blood spaces of the tumor stroma are compressed by the swollen, hydropic tumor cells, the trabecular pattern is often obscured and the tumor takes on a solid appearance. The tumor contains many arterial and venous tumor vessels, and pelioid change is frequently observed.

\subsection{Focal nodular hyperplasia (FNH)}

FNH is not a true neoplasm, but rather a regenerative hyperplastic response of hepatocytes, secondary to localized vascular abnormalities with a marked female preponderance [Wanless et al., 1985; Fukukura et al., 1998]. This lesion was reported as liver cell adenoma for many years before the disease concept of FNH was defined by Edmondson in 1958 [Edmondson, 1958]. In two-thirds of cases, FNH is solitary [Wanless et al., 1989]. Most lesions are asymptomatic and discovered incidentally during laparotomy, autopsy or imaging studies for unrelated symptoms. Although it can now be precisely diagnosed by various imaging modalities, FNH is still considered one of the common lesions in the differential diagnosis of HCC. The size of FNH varies from a few millimeters to over $10 \mathrm{~cm}$ in diameter. Grossly, FNH is usually well demarcated, but not encapsulated. Most tumors are located close to the liver capsule, and $4.6-20 \%$ are reportedly pedunculated [Ishak, 1975; Klatskin, 1977; Luciani et al., 2002]. One of the characteristic gross features of FNH is the presence of a central fibrous scar with radiating fibrous bands dividing the tumor into lobules. The reported incidence of a central scar in FNH is 49-62.8\% [Nguyen et al., 1999; Kojiro, 2006]. Histologically, classical FNH lesions are composed of benign hepatocytes arranged in a trabecular pattern of one- or two-cell-thick plates. The central scar consists of dense fibrous tissue with many artery-like or vein-like anomalous blood vessels and ductal proliferations. Hyperplastic features of hepatocytes in FNH comprise increased cellularity with an increased nuclear cytoplasmic ratio, an irregular thin trabecular pattern, and a pseudoglandular pattern. Areas showing prominent hyperplastic features mimic welldifferentiated HCC. 


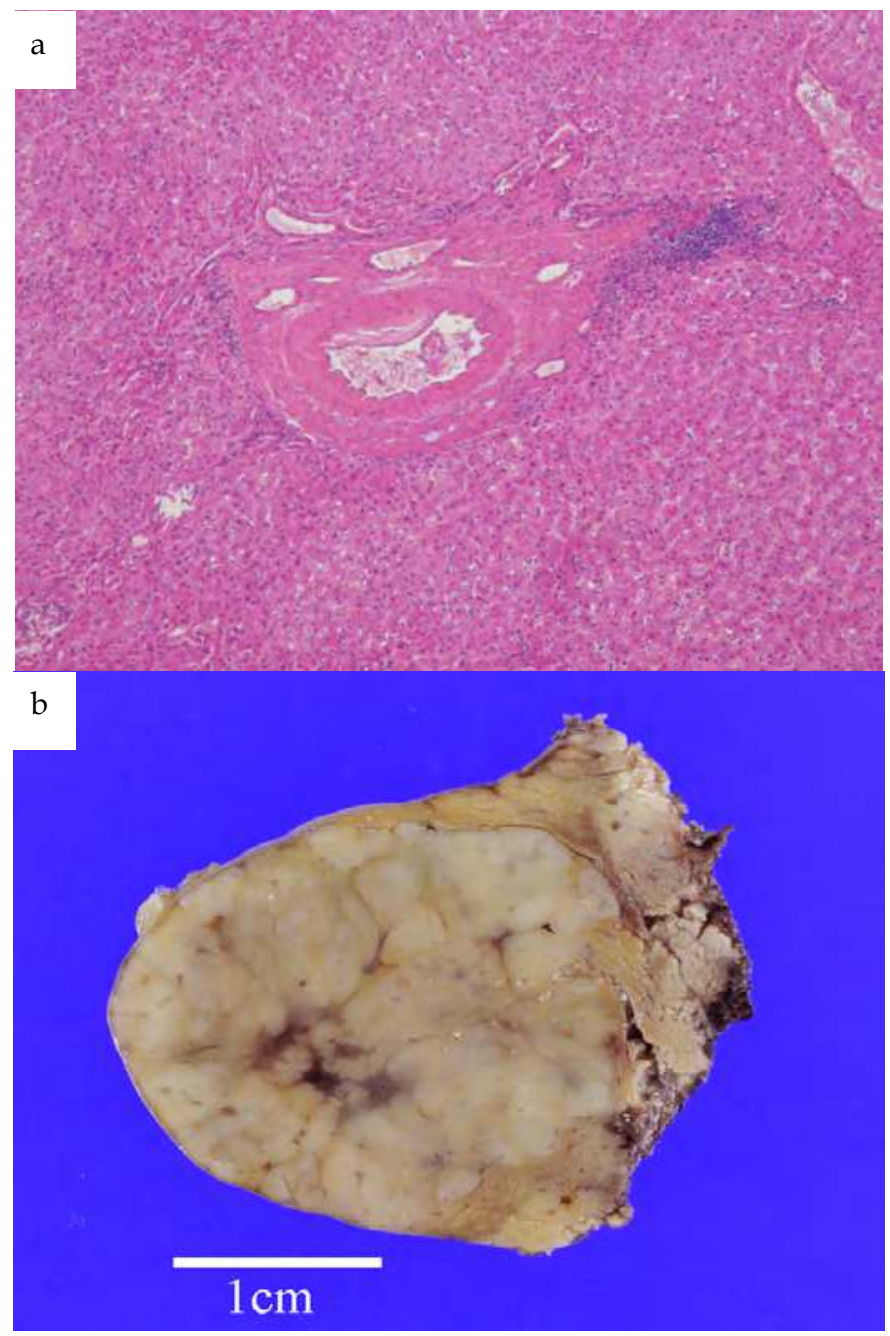

Fig. 16. a) Gross appearance of FNH. A faint central fibrous scar is apparent in this case. b) Artery-like anomalous blood vessels are observed in benign hepatocytes $(\mathrm{HE}, \times 40)$.

\subsection{Hepatocellular neoplasm with massive histiocyte infiltration}

HCC usually contains various degrees of histiocyte infiltration. In the authors' institution, a case of unique hepatocellular nodule with infiltration of abundant histiocytes not previously described has been encountered [Kai, 2010]. This case involved a 73-year-old Japanese man with diabetes mellitus and mild obesity without viral hepatitis. Histologically, the nodule consisted of hepatocyte-like tumor cells and abundant foam cell-type histiocytes that filled up a sinusoidlike space and formed central loose fibrosis. The tumor showed characteristics of hepatocellular adenoma, but contained a focal HCC-like lesion. Similar hepatic nodules have not been reported and most of the clinicopathological features and pathology remain unknown. 


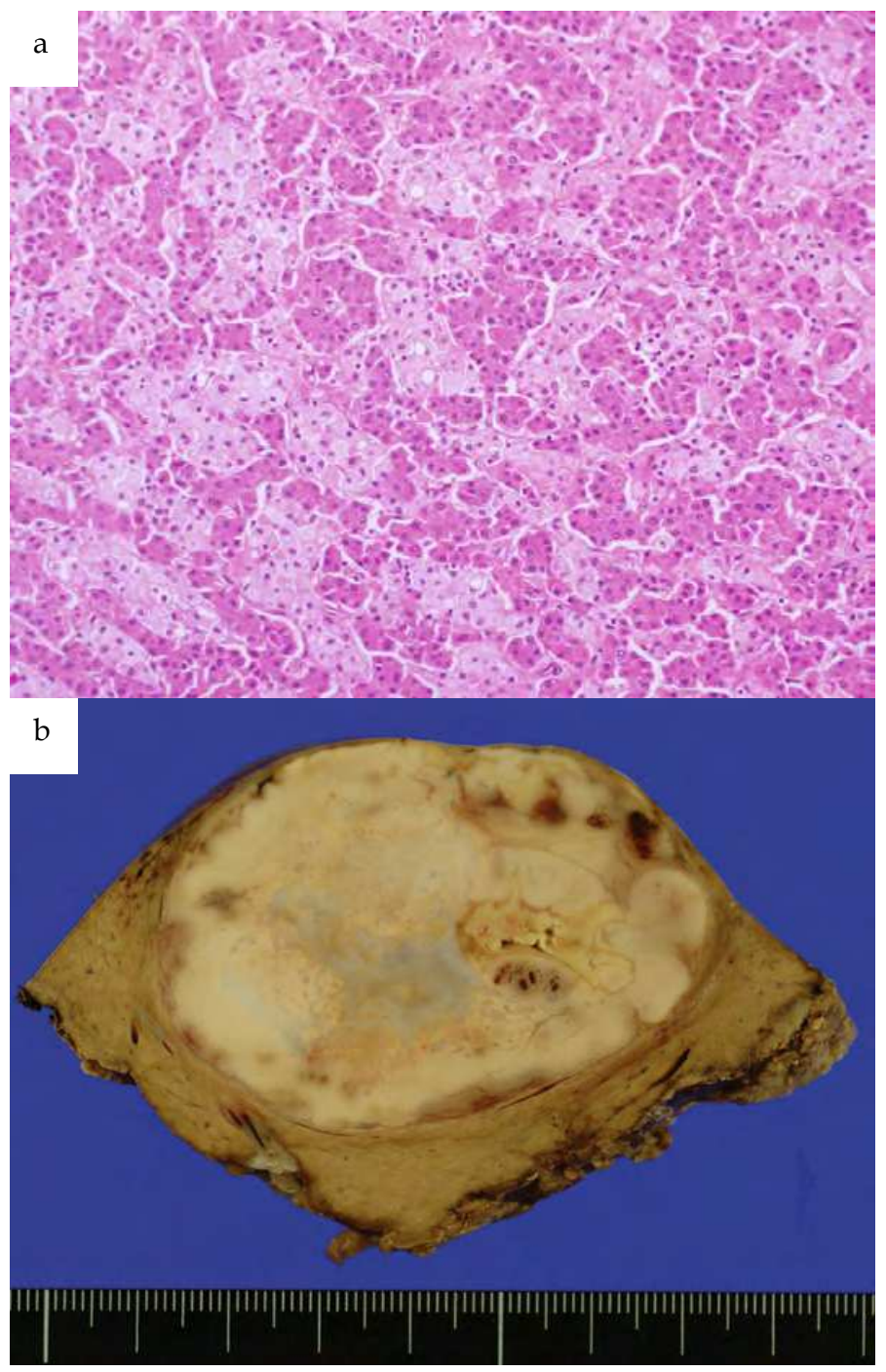

Fig. 17. a) Gross appearance of hepatocellular neoplasm with massive histiocyte infiltration. The nodule was solitary, and the cut surface was whitish with a partly necrotic yellowish area. A white myxoid fibrotic area was found at the center of the nodule. b) The nodule showed a two-cell pattern: hepatocyte-like cells with rich eosinophilic cytoplasm and little nuclear atypia; and light-pink cells considered to be foam cell-type histiocytes $(\mathrm{HE}, \times 100)$.

\subsection{Primary squamous cell carcinoma (SCC) of the liver}

Primary SCC of the liver is very rare. Adenosquamous carcinoma of the liver is also rare and reported only sporadically. Various theories have been advanced concerning the pathogenesis of SCC of the liver. Chronic inflammation of the bile duct and various 

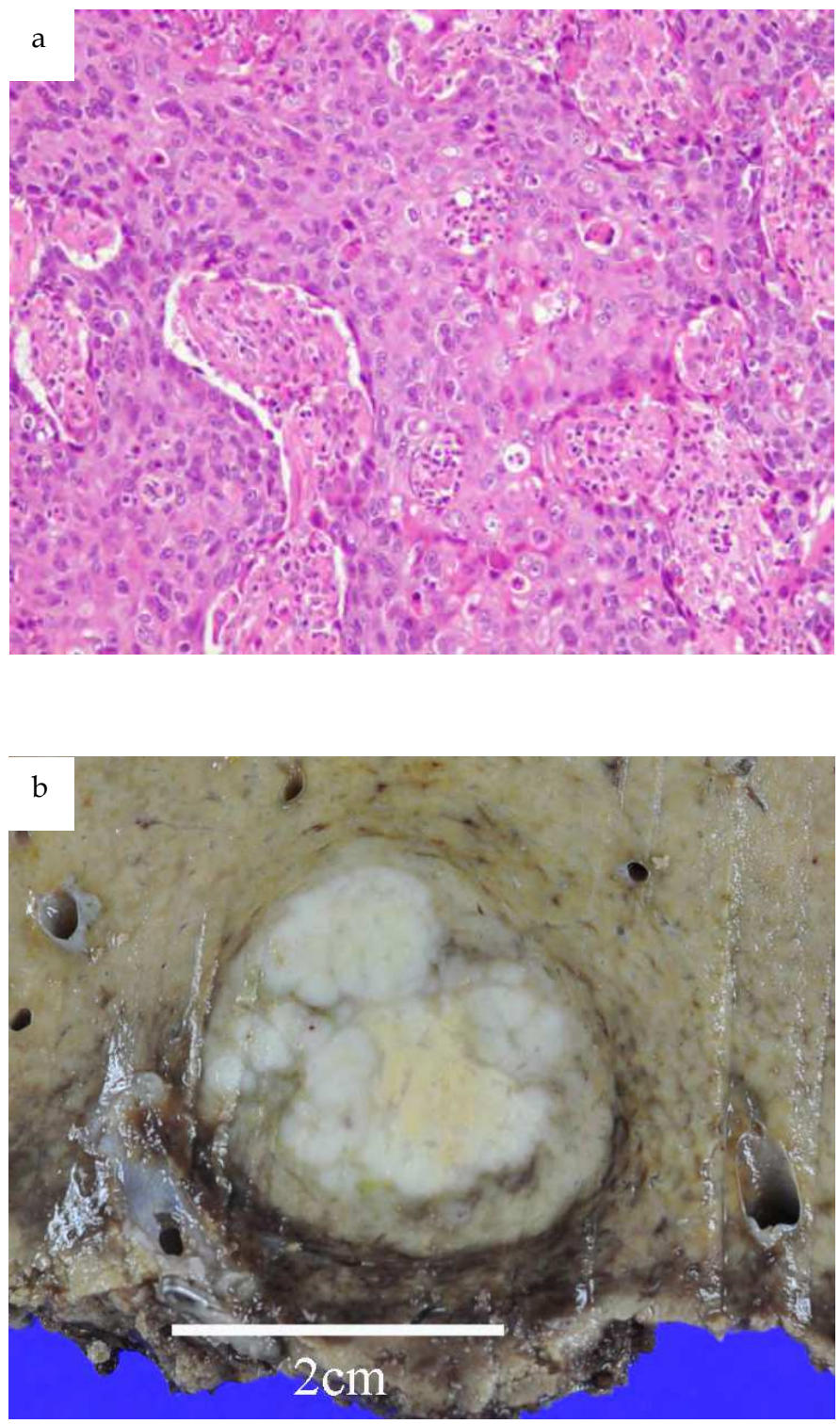

Fig. 18. a) Gross appearance of primary pure SCC of the liver in a patient with no history of prior liver insult. b) The nodule consists entirely of SCC tissue with or without keratinization. 

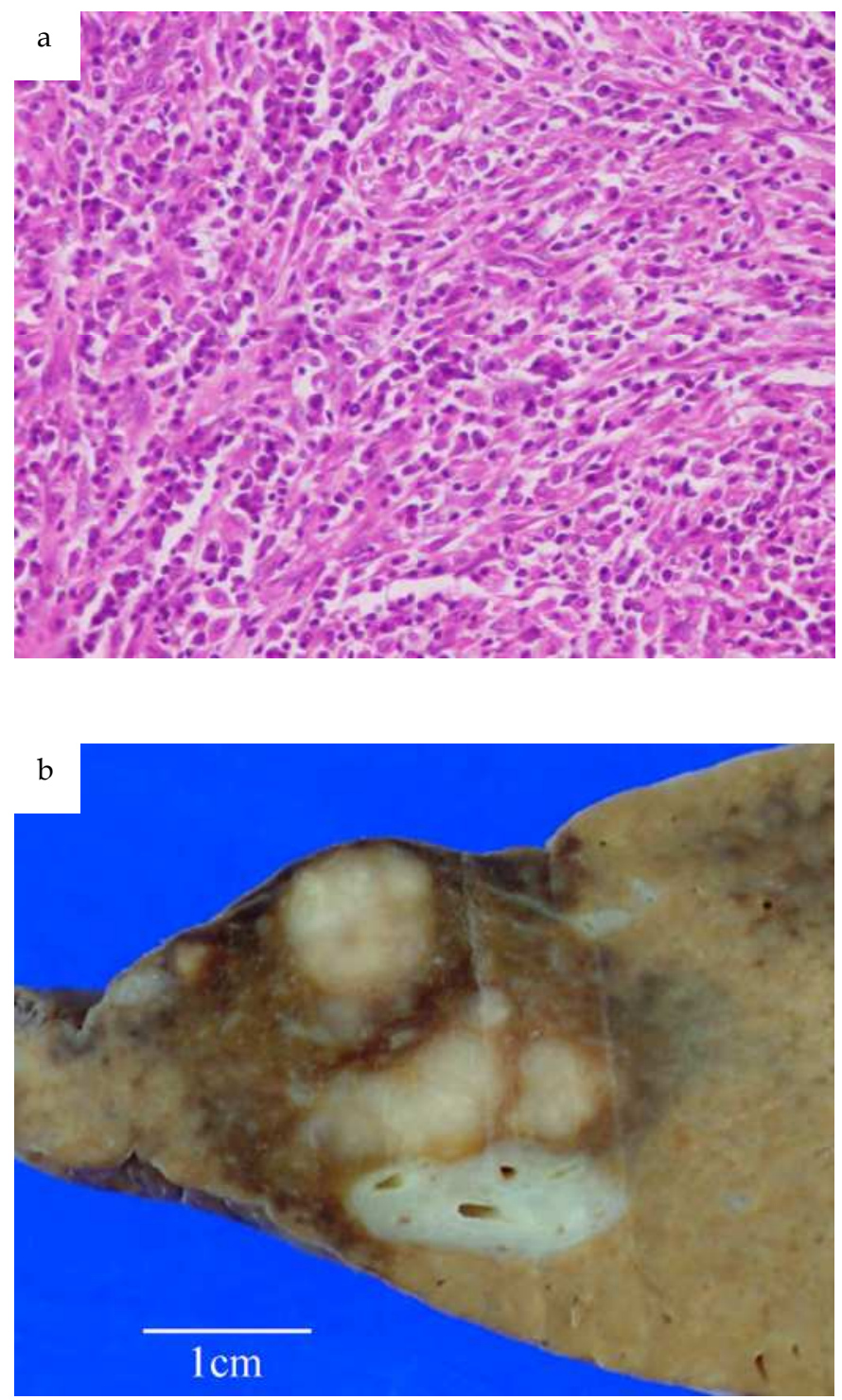

Fig. 19. a) A cross-section of inflammatory pseudotumor. Small, white nodules without fibrous capsules are observed. b) The tumor comprises chronic inflammatory cells, predominantly representing plasma cells $(\mathrm{HE}, \times 200)$. 
congenital cysts of the biliary tract have been proposed as etiological factors and continuous irritation due to chronic infection, followed by metaplastic changes in the biliary epithelium, has been thought to lead to neoplasia [Clements et al., 1990; Nieweg et al., 1992; Banbury et al., 1994]. On the other hand, some investigators have suggested that adenosquamous carcinoma could arise from squamous metaplasia of adenocarcinoma cells [Barr and Hancock, 1975; Tomioka et al., 1987]. Primary SCC of the liver without history of prior liver insult suggesting development from squamous metaplasia of adenocarcinoma cells has recently been reported [Naik et al., 2009]. Gross appearance depends on the presence or absence of congenital cysts. The mass lesion in that case appeared as a solid, whitish firm mass without fibrous capsule and with a necrotic area of keratin deposits observed inside the nodule.

\subsection{Inflammatory pseudotumor / inflammatory myofibroblastic tumor}

Inflammatory pseudotumor is defined as a benign, non-neoplastic mass consisting of fibrous tissue and proliferated myofibroblasts and fibroblasts, with marked infiltration of chronic inflammatory cells, predominantly comprising polyclonal plasma cells, histiocytes, and macrophages [Coffin et al., 1995]. Lesions of known cause, such as healing abscess, tuberculosis, and parasitic infestations, and post-traumatic granulation tissue, are excluded from this category. Patients with hepatic lesions generally complain of recurrent fever, malaise, abdominal pain, vomiting, and/or diarrhea, but those clinical symptoms are not specific. The morphology of inflammatory pseudotumor apparently differs according to the stage of inflammation when the lesion is detected. Grossly, the lesion appears as a yellowish or whitish nodule with relatively clear margins and a widely varying diameter, usually within the range of $1-3 \mathrm{~cm}$. Histological appearance also varies considerably, sometimes consisting of nonspecific inflammatory granulation tissue with prominent plasma cell infiltration, sometimes associated with necrotic foci, and sometimes appearing as a scar-like fibrous nodule with mild inflammatory cell infiltration [Kojiro, 2006]. Phlebitis involving peripheral portal or hepatic veins is often seen. Rarely, major hepatic and/or portal veins or the vena cava are involved by phlebitis mimicking malignant tumor [Broughan et al., 1993; Kai et al., 2007]. Lately, IgG4-related disease has been identified as an important subgroup of inflammatory pseudotumor [Zen et al., 2004, 2007]. Inflammatory myofibroblastic tumor has recently been considered as a possible neoplastic counterpart of inflammatory pseudotumor [Coffin et al., 1998], based on the finding that approximately half of inflammatory myofibroblastic tumors show an ALK gene translocation [Lawrence et al., 2000; Bridge et al., 2001; Chan et al., 2001].

\section{Conclusion}

This chapter documented the gross appearance and pathology of various types of tumor, along with a review of the literature. We believe that the observation of gross features with contrasting pathological and clinical findings is helpful in clarifying the nature of tumors. In rare cases, a picture of the gross specimen is necessary for case reports. Careful storage of good-quality images of gross specimens is thus important in daily clinical work. 


\section{References}

Banbury J, Conlon KC, Ghossein R, et al. (1994). Primary squamous cell carcinoma within a solitary nonparasitic hepatic cyst. J Surg Oncol, 57, pp.210-212.

Barr RJ, Hancock DE (1975). Adenosquamous carcinoma of the liver. Gastroenterology, 69, pp.1326-1330

Bosman FT, Carnerio F, Hruban RH, Theise ND, Eds. (2010) WHO classification of Tumors of the Digestive System. IARC, Lyon.

Bridge JA, Kanamori M, Ma Z, et al. (2001). Fusion of the ALK gene to the clathrin heavy chain gene, CLTC, in inflammatory myofibroblastic tumor. Am J Pathol., 159, pp.411-415.

Broughan TA, Fischer WL, Tuthill RJ. (1993). Vascular invasion by hepatic infl ammatory pseudotumor. A clinicopathologic study. Cancer, 71, pp.2934-2940.

Chan JK, Cheuk W, Shimizu M. (2001), Anaplastic lymphoma kinase in inflammatory pseudotumors. Am J Surg Pathol., 25, pp.761-768.

Chen MF, Jan YY, Jeng LB, et al. (1994). Obstructive jaundice secondary to ruptured hepatocellular carcinoma into the common bile duct. Surgical experiences of 20 cases. Cancer, 73, pp.1335-1340.

Clements D, Newman P, Etherington R,et al. (1990). Squamous carcinoma in the liver. Gut, 31, pp.1333-1334.

Coffin CM, Dehner LP, Meis-Kindblom JM. (1998). Inflammatory myofibroblastic tumor, inflammatory fibrosarcoma, and related lesions: an historical review with differential diagnostic considerations. Semin Diagn Pathol., 15, pp.102110.

Coffin CM, Watterson J, Priest JR, et al. (1995). Extrapulmonary inflammatory myofi broblastic tumor (inflammatory pseudotumor). A clinicopathologic and immunohistochemical study of 84 cases. Am J Surg Pathol.,19(8), pp.859-872.

Craig JR, Peters RL, Edmondson HA, et al. (1980). Fibrolamellar carcinoma of the liver: a tumor of adolescents and young adults with distinctive clinico-pathologic features. Cancer, 15, 46(2), pp.372-379.

Edmondson HA. (1958). Focal nodular hyperplasia. In: Atlas of Tumor Pathology: Tumors of the Liver and Intrahepatic Bile Ducts, 1st Series, Fascicle 25. Armed Forces Institute of Pathology, Washington DC, pp. 193-195.

Edmondson HA. (1958). Hepatocelllar carcinoma. In: Atlas of Tumor Pathology: Tumors of the Liver and Intrahepatic Bile Ducts, 1st Series, Fascicle 25. Armed Forces Institute of Pathology, Washington DC, pp. 32.

Eggel, H. (1901). Uber das prime Carcinoma der Leber. Beitr Pathol Anat Allg Pathol, 30, pp.506-604.

Fukukura Y, Nakashima O, Kusaba A, et al. (1998). Angioarchitecture and blood circulation in focal nodular hyperplasia of the liver. J Hepatol., 29(3), 470-475.

Gaffey MJ, Joyce JP, Carlson GS, et al. (1990). Spontaneous regression of hepatocellular carcinoma. Cancer, 65, pp.2779-2783.

Gottfried EB, Steller R, Paronetto F, et al. (1982). Spontaneous regression of hepatocellular carcinoma. Gastroenterology, 82, pp.770-774 
Hoshimoto S, Morise Z, Suzuki K, et al. (2009). Hepatocellular carcinoma with extensive peliotic change. J Hepatobiliary Pancreat Surg.,16, pp.566-570.

$\mathrm{Hu}$ J, Pi Z, Yu MY, et al. (1999). Obstructive jaundice caused by tumor emboli from hepatocellular carcinoma. Am Surg., 65(5), pp.406-410.

Huang GT, Sheu JC, Lee HS, rt al. (1998). Icteric type hepatocellular carcinoma: revisited 20 years later. J Gastroenterol., 33(1), pp. 53-56.

Hui AM, Takayama T, Sano K, et al. (2000). Predictive value of gross classification of hepatocellular carcinoma on recurrence and survival after hepatectomy. J Hepatol., 33(6), pp.975-979.

Imaoka S, Sasaki Y, Masutani S, et al. (1994). Necrosis of hepatocellular carcinoma caused by spontaneously arising arterial thrombus. Hepatogastroenterology, 41, pp.359-362.

Inayoshi J, Ichida T, Sugitani S, et al. (2003) Gross appearance of hepatocellular carcinoma reflects E-cadherin expression and risk of early recurrence after surgical treatment. J Gastroenterol Hepatol., 18(6), pp.673-677.

Ishak KG, Goodman ZD, StockerJT. (1999). Hepatocelllar carcinoma. In: Atlas of Tumor Pathology: Tumors of the Liver and Intrahepatic Bile Ducts, 3rd Series, Fascicle 31. Armed Forces Institute of Pathology, Washington DC.

Ishak KG, Rabin L. (1975). Benign tumors of the liver. Med Clin North Am., 59(4), pp.9951013.

Kai K, Matsuyama S, Ohtsuka T, et al. (2007). Multiple inflammatory pseudotumor of the liver, mimicking cholangiocarcinoma with tumor embolus in the hepatic vein: report of a case. Surg Today., 37(6), pp.530-533.

Kai K, Miyoshi A, Ario K, et al. (2010). The two cases of massive spontaneous necrosis of hepatocellular carcinoma after angiography. Kanzo , 51, pp.312-318.

Kai K, Miyoshi A, Egashira Y, et al. (2011). A case of Pelioid type of Hepatocellular carcinoma composed of the two different nodules. Kanzo, 52(2), pp.112-119.

Kai K, Miyoshi A, Tokunaga O, et al. (2010) A hepatocellular neoplasm accompanied with massive histiocyte infiltration. Clin J Gastroenterol, 3, pp.40-44.

Kanai T, Hirohashi S, Upton MP, et al. (1987) Pathology of small hepatocellular carcinoma. A proposal for a new gross classification. Cancer, 15, 60(4), pp.810-819.

Kim YK, Jang KY, Cho BH, et al. (2007). Three-phase dynamic CT of pelioid hepatocellular carcinoma. Am J Roentgenol., 189, pp.160-162.

Kirk JM, Skipper D, Joseph AE, et al. (1994). Intraluminal bile duct hepatocellular carcinoma. Clin Radiol, 49, pp. 886-888.

Klatskin G. (1977). Hepatic tumors: possible relationship to use of oral contraceptives. Gastroenterology., 73(2), 386-394.

Kojiro M, Kawabata K, Kawano Y, et al. (1982). Hepatocellular carcinoma presenting as intrabile duct tumor growth: a clinicopathologic study of 24 cases. Cancer., 15, 49(10), pp.2144-2147.

Kojiro M, Nakashima O. (1999). Histopathologic evaluation of hepatocellular carcinoma with special reference to small early stage tumors. Semin Liver Dis, 19(3), pp.287296. 
Kojiro M. (2006). Pathology of Hepatocellular Carcinoma, Blackwell publishing inc., Massachusetts.

Kojiro M. (2007) Diagnostic discrepancy of early hepatocellular carcinoma between Japan and West. Hepatology Research, 37 (Suppl. 2), pp.S121-S124.

Kondo F, Kondo Y, Nagato Y, et al. (1994). Interstitial tumour cell invasion in small hepatocellular carcinoma. Evaluation in microscopic and low magnification views. J Gastroenterol Hepatol, 9(6), pp. 604-612.

Kurogi M, Nakashima O, Miyaaki H, et al. (2006) Clinicopathological study of scirrhous hepatocellular carcinoma. J Gastroenterol Hepatol., 21(9), pp.1470-1477.

Lam KC, Ho JC, Yeung RT. (1982). Spontaneous regression of hepatocellular carcinoma: a case study. Cancer, 50, pp.332-336

Lau W, Leung K, Leung TW, et al. (1997). A logical approach to hepatocellular carcinoma presenting with jaundice. Ann Surg., 225(3), pp.281-285.

Lawrence B, Perez-Atayde A, Hibbard MK, et al. (2000). TPM3-ALK and TPM4-ALK oncogenes in inflammatory myofibroblastic tumors. Am J Pathol., 157, pp.377384.

Lin TY. (1972). Tumors of the liver, part 1: primary malignant tumors. In : Bockus HL, Berk JE, Haubrich WS, et al. (eds). Gastroenterology, 3rd edn. WB Saunders, Philadelphia, pp.527.

Liver Cancer Study Group of Japan. (1987). General Rules for the Clinical and Pathological Study of Primary liver cancer, 2nd edn. Kanehara, Tokyo.

Liver Cancer Study Group of Japan. (2000). General Rules for the Clinical and Pathological Study of Primary liver cancer, 4th edn. Kanehara, Tokyo.

Long XY, Li YX, Wu W,et al. (2010). Diagnosis of bile duct hepatocellular carcinoma thrombus without obvious intrahepatic mass. World J Gastroenterol., 21, 16(39), pp. 4998-5004.

Luciani A, Kobeiter H, Maison P, et al. (2002). Focal nodular hyperplasia of the liver in men: is presentation the same in men and women? Gut, 50(6), 877-880.

Magata S, Kitahara K, Watanabe K, et al. (2001). Fibrolamellar hepatocellular carcinoma-a case report. Kanzo, 42(8), pp.414-419.

Markovic S, Ferlan-Marolt V, Hlebanja Z. (1996). Spontaneous regression of hepatocellular carcinoma. Am J Gastroenterol; 91, pp.392-393.

McCaughan GW, Bilous MJ, Gallagher ND. (1985) Long-term survival with tumor regression in androgen-induced liver tumors. Cancer, 56, pp.2622-2626.

Naik S, Waris W, Carmosino L, et al. (2009). Primary squamous cell carcinoma of the liver. J Gastrointestin Liver Dis., 18(4), 487-489.

Nakajima T, Moriguchi M, Watanabe T, et al. (2004). Recurrence of hepatocellular carcinoma with rapid growth after spontaneous regression. World J Gastroenterol., 15, 10(22), pp.3385-3387.

Nakano M, Saito A, Yamamoto M, et al. (1997). Stromal and blood vessel wall invasion in well-differentiated hepatocellular carcinoma. Liver, 17(1), pp.41-46.

Nakashima Y, Nakashima O, Hsia CC, et al. (1999). Vascularization of small hepatocellular carcinomas: correlation with differentiation. Liver, 19(1), pp.12-18. 
Nguyen BN, Fléjou JF, Terris B, et al. (1999). Focal nodular hyperplasia of the liver: a comprehensive pathologic study of 305 lesions and recognition of new histologic forms. Am J Surg Pathol., 23(12), 1441-1454.

Nieweg O, Slooff MJ, Grond J. (1992). A case of primary squamous cell carcinoma of the liver arising in a solitary cyst. HPB Surg, 5, pp.203-208.

Rooks JB, Ory HW, Ishak KG, et al. (1979). Epidemiology of hepatocellular adenoma. The role of oral contraceptive use. JAMA., 17, 242(7), pp.644-648.

Shimada M, Rikimaru T, Hamatsu T, et al. (2001). The role of macroscopic classification in nodular-type hepatocellular carcinoma. Am J Surg., 182(2), pp.177-182.

Shiota K, Taguchi J, Nakashima O, et al. (2001) Clinicopathologic study on cholangiolocellular carcinoma. Oncol Rep., 8(2), pp.263-268.

Shuangshoti S, Thaicharoen A. (1994). Hepatocellular adenoma in a beta-thalassemic woman having secondary iron overload. J Med Assoc Thai., 77(2), pp.108-112.

Soreide O, Czerniak A, Bradpiece H, et al. (1986). Characteristics of fibrolamellar hepatocellular carcinoma. A study of nine cases and a review of the literature. Am J Surg., 151(4), pp.518-523.

Soyer P, Laissy JP, Bluemke DA, et al. (1995). Bile duct involvement in hepatocellular carcinoma: MR demonstration. Abdom Imaging., 20(2), pp.118-121.

Steiner PE, Higginson J. (1959) Cholangiolocellular carcinoma of the liver. Cancer., 12(4), pp.753-759.

Suzuki M, Okazaki N, Yoshino M. (1989). Spontaneous regression of a hepatocellular carcinoma: a case report. Hepatogastroenterology, 36, pp.160-163.

Takayasu K, Muramatsu Y, Shima Y, et al. (1986). Necrosis of hepatocellular carcinoma as a result of subintimal injury incurred by hepatic angiography: report of two cases. Am J Gastroenterol., 81, pp.979-983.

Tocci G, Conte A, Guarascio P, et al. (1990). Spontaneous remission of hepatocellular carcinoma after massive gastrointestinal haemorrhage. BMJ., 300, pp.641-642.

Tomioka T, Tsunoda T, Harada N, et al. (1987). Adenosquamous carcinoma of the liver. Am J Gastroenterol., 82, pp.1203-1206.

Tomizawa M, Kondo F, Kondo Y. (1995). Growth patterns and interstitial invasion of small hepatocellular carcinoma. Pathol Int., 45(5), pp.352-358.

Velazquez I, Alter BP. (2004). Androgens and liver tumors: Fanconi's anemia and nonFanconi's conditions. Am J Hematol., 77(3), pp.257-267.

Wang JH, Chen TM, Tung HD, et al. (2002). Color Doppler sonography of bile duct tumor thrombi in hepatocellular carcinoma. J Ultrasound Med., 21(7), pp.767-772.

Wanless IR, Albrecht S, Bilbao J, et al. (1989). Multiple focal nodular hyperplasia of the liver associated with vascular malformations of various organs and neoplasia of the brain: a new syndrome. Mod Pathol., 2(5), 456-462.

Wanless IR, Mawdsley C, Adams R. (1985). On the pathogenesis of focal nodular hyperplasia of the liver. Hepatology., 5(6), pp.1194-1200.

Watanabe N, Yamauchi N, Maeda M, et al. (1994). Recombinant human tumor necrosis factor causes regression in patients with advanced malignancies. Oncology, 51, pp.360-365 
Zen Y, Fujii T, Sato Y, et al. (2007). Pathological classification of hepatic inflammatory pseudotumor with respect to IgG4-related disease. Mod Pathol., pp.884-894.

Zen Y, Harada K, Sasaki M, et al. (2004). IgG4-related sclerosing cholangitis with and without hepatic inflammatory pseudotumor, and sclerosing pancreatitis-associated sclerosing cholangitis: do they belong to a spectrum of sclerosing pancreatitis? Am J Surg Pathol., 28(9), pp.1193-1203. 


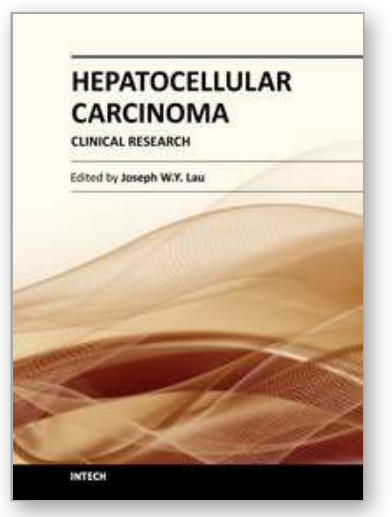

\author{
Hepatocellular Carcinoma - Clinical Research \\ Edited by Dr. Joseph W.Y. Lau
}

ISBN 978-953-51-0112-3

Hard cover, 330 pages

Publisher InTech

Published online 02, March, 2012

Published in print edition March, 2012

This book covers the clinical aspects of hepatocellular carcinoma. This book is a compendium of papers written by experts from different parts of the world to present the most up-to-date knowledge on the clinical aspects of hepatocellular carcinoma. This book is divided into three sections: (I) Diagnosis / Differential Diagnosis; (II) Surgical Treatment; (III) Non-surgical Treatment. There are 19 chapters covering topics from novel diagnostic methods to hepatic lesions mimicking hepatocellular carcinoma, from laparoscopic liver resection to major hepatectomy without allogeneic blood transfusion, from molecular targeted therapy to transarterial radioembolization, and from local ablative therapy to regional therapy. This volume is an important contribution to the clinical management of patients with hepatocellular carcinoma. The intended readers of this book are clinicians who are interested in hepatocellular carcinoma, including hepatologists, liver surgeons, interventional and diagnostic radiologists, pathologists and epidemiologists. General surgeons, general physicians, trainees, hospital administrators, and instruments and drug manufacturers will also find this book useful as a reference.

\title{
How to reference
}

In order to correctly reference this scholarly work, feel free to copy and paste the following:

Keita Kai, Atsushi Miyoshi, Kenji Kitahara, Kohji Miyazaki, Hirokazu Noshiro and Osamu Tokunaga (2012). Usual and Unusual Gross Appearance of Hepatocellular Carcinomas, Hepatocellular Carcinoma - Clinical Research, Dr. Joseph W.Y. Lau (Ed.), ISBN: 978-953-51-0112-3, InTech, Available from: http://www.intechopen.com/books/hepatocellular-carcinoma-clinical-research/usual-and-unusual-grossappearance-of-hepatocellular-carcinomas

\section{INTECH}

open science | open minds

\section{InTech Europe}

University Campus STeP Ri

Slavka Krautzeka 83/A

51000 Rijeka, Croatia

Phone: +385 (51) 770447

Fax: +385 (51) 686166

www.intechopen.com

\section{InTech China}

Unit 405, Office Block, Hotel Equatorial Shanghai

No.65, Yan An Road (West), Shanghai, 200040, China

中国上海市延安西路65号上海国际贵都大饭店办公楼 405 单元

Phone: +86-21-62489820

Fax: +86-21-62489821 
(C) 2012 The Author(s). Licensee IntechOpen. This is an open access article distributed under the terms of the Creative Commons Attribution 3.0 License, which permits unrestricted use, distribution, and reproduction in any medium, provided the original work is properly cited. 